\title{
Ueber die Gewinnung des Lithions aus Triphyllin;
}

\author{
von Hugo Miller.
}

Der Triphyllin, welcher in Begleitung von Beryll, Turmalin, Columbit und Eisenapatit nesterweise in einem sehr grobkörnigen Ganggranit am Rabenstein bei Zwiesel im bayerischen Walde vorkommt, ist wegen seines grofsen Gehaltes an Lithion und seiner Auflüslichkeit in Säuren das zweckmäfsigste Material zur Darstellung dieses seltenen Alkalis. Ich wendete dazu das folgende Verfahren an, welches, wie ich denke, vor den bisher angewandten mancherlei Vorzüge darbietet.

Das gröblich zerstofsene Mineral wird unter allmäligem Zusalz von Salpetersäure in concentrirter Salzsäure gelöst; die erhaltene Lösung, die alles Eisen als 0xyd enthalten mufs, wird von dem unlöslichen, gewöhnlich aus Feldspath, Beryll und Glimmer bestehenden Rückstand abgegossen, unter stetem Umrühren zur vollständigen Trockne abgedampft und so lange erhitzt, bis alle freie Säure verdampft ist. Die zurückbleibende, etwas lyygroscopische Masse wird möglichst fein gepulvert, mit Wasser ausgekocht und die Lösung abfiltrirt. War die Operation gut ausgeführt und war alles Eisen in 0xyd verwandell, so enthält nun diese Lösung keine Spur von Eisen, sondern nur die Chlorüre von Lithium, Mangan und Magnesium, denn in dem Mafse wie die Säure verdampft, welche das phosphorsaure Eisenoxyd gelüst enthielt, schlägt sich dieses in Form eines schweren weilsen Pulvers nieder. Da dieser Niederschlag sehr dicht ist, so läfst er sich sehr leicht abfiltriren und auswaschen. Um nun das Mangan und die Magnesia vom Lithion zu trennen, wird die Lösung mit frischbereitetem Kalkhydrat im Ueberschuls vermischt und unter Luftzutritt gekocht, bis sich das ausgeschiedene Manganoxydulhydrat hoher oxydirt hat. Der braune Niederschlag enthält, 
252 Müller, über d. Gewinnung des Lithions aus Triphyllin.

aufser dem Mangan und überschüssigen Kalkhydrat, auch die Magnesia *) und die allenfalls noch in Lösung gewesene Phosphorsäure. Alles Lithion bleibt in der Lösung; sie wird abfiltrirt und die aufgelöste Kalkerde durch ein Gemisch von kaustischem und kohlensaurem Ammoniak ausgefällt. Nach dem Filtriren wird sie abgedampft und das zurückbleibende Chlorlithium in Porcellantiegel bis zum Schmelzen erhitzt. Es enthält noch eine kleine Menge Chlornatrium beigemengt, welches aber hinreicht, die characteristische dunkelcarmoisinrothe Färbung, welche reines Lithion der Flamme ertheilt, in orangeroth umzuwandeln. Man kann dieses Chlornatrium nach der Methode von Rammelsberg entfernen, indem man die Masse mil einem Gemische von Alkohol und Aether macerirt, welches das Chlorlithium löst, das Chlornatrium aber ungelöst lärst. Will man indessen vollkommen reines Lithion erhalten, so ist es vorzuziehen, das rohe Chlorlithium in kohlensaures Salz zu verwandeln, und zwar dadurch, dafs man das Salz in der kleinsten erforderlichen Menge concentrirten kaustischen Ammoniaks auflüst und in diese möglichst kalt gehaltene Lösung Stückchen von kohlensaurem Ammoniak legt. In der Wärme und besonders in der Siedhitze würde sich das kohlensaure Lithion mil Chlorammonium wieder in Chlorlithium und kohlensaures Ammoniak umsetzen. Das in der Källe gefälte kohlensaure Lithion wird auf ein Filter gebracht und mil Alkohol ausgewaschen, wodurch das Chlornatrium entfernt wird.

*) Magnesia findet sich gewöhnlich nur in sehr geringer Menge in dem Triphyllin und scheint nicht dem Triphyllin selbst, sondern den ihn begleitenden Mineralien anzugebören. 